\title{
Conditions for one direction convexity and starlikeness
}

\author{
Mamoru Nunokawa', Oh Sang Kwon², Young Jae Sim², Ji Hyang Park ${ }^{3}$ and Nak Eun Cho ${ }^{3 *}$
}

\section{"Correspondence:}

necho@pknu.ac.kr

${ }^{3}$ Department of Applied

Mathematics, Pukyong National

University, Busan, 48513, Korea

Full list of author information is

available at the end of the article

\begin{abstract}
We investigate several sufficient conditions on a function to be convex in one direction or starlike in one direction.
\end{abstract}

MSC: Primary 30C45

Keywords: analytic functions; univalent functions; convex functions in one direction; starlike functions in one direction

\section{Introduction}

Let $\mathcal{H}$ denote the class of functions analytic in the unit disk $\mathbb{D}:=\{z \in \mathbb{C}:|z|<1\}$, and denote by $\mathcal{A}$ the class of analytic functions in $\mathcal{H}$ that are normalized by $f(0)=0=f^{\prime}(0)-1$. Also, let $\mathcal{S}$ denote the subclass of $\mathcal{A}$ composed of functions that are univalent in $\mathbb{D}$.

We say that a function $f$ is starlike in one direction if $f$ it maps $|z|=r$ for every $r$ near 1 onto a contour $C$ that is cut by a straight-line passing through the origin in two and no more than two points. Robertson [1] found the following sufficient condition for starlikeness in one direction.

Lemma 1 Let $f(z)$ be analytic in $|z| \leq r$, and $f(z) \neq 0$ in $0<|z| \leq r$. Further, let $f(0)=0$. Suppose that

$$
\int_{0}^{2 \pi}\left|\mathfrak{R} \frac{z f^{\prime}(z)}{f(z)}\right| \mathrm{d} \theta<4 \pi, \quad z=\rho \mathrm{e}^{i \theta}, \text { for every } \rho \leq r
$$

Then, for every $\rho \leq r, f(z)$ maps $|z|=\rho$ onto a curve that is starlike in one direction.

A function is said to be convex in one direction in $|z|<r(r>0)$ if the function maps $|z|=\rho<r$ for every $\rho$ near $r$ into a contour that may be cut by every straight-line parallel to this direction in no more than two points. It is known (see [1]) that if $f \in \mathcal{A}$ and $z f^{\prime}(z)$ is starlike in one direction, then $f(z)$ is convex in one direction and belongs to $\mathcal{S}$. Therefore, we can obtain the following lemma (see also [2-4]).

Lemma 2 Let $f(z)=z+\sum_{n=2}^{\infty} a_{n} z^{n}$ beanalyticfor $|z| \leq 1$ and $f^{\prime}(z) \neq 0$ on $|z|=r<1$. Suppose that

(C) 2016 Nunokawa et al. This article is distributed under the terms of the Creative Commons Attribution 4.0 International License (http://creativecommons.org/licenses/by/4.0/), which permits unrestricted use, distribution, and reproduction in any medium, provided you give appropriate credit to the original author(s) and the source, provide a link to the Creative Commons license, and indicate if changes were made. 


$$
\int_{0}^{2 \pi}\left|1+\Re\left\{\frac{z f^{\prime \prime}(z)}{f^{\prime}(z)}\right\}\right| \mathrm{d} \theta<4 \pi, \quad z=r \mathrm{e}^{i \theta}, \text { for every } r<1 .
$$

Then $f(z)$ is convex in one direction, and hence $f(z)$ is univalent in $|z| \leq 1$.

We may refer to [5-7] for more sufficient conditions on analytic functions to be convex in one direction.

In the present paper, we investigate several sufficient conditions on functions in $\mathcal{A}$ to be convex in one direction using various methods. Also, we find sufficient conditions for starlikeness in one direction.

\section{Main results}

Theorem 1 Let $f(z) \in \mathcal{A}$ and suppose that

$$
\left|1+\mathfrak{R}\left\{\frac{z f^{\prime \prime}(z)}{f^{\prime}(z)}\right\}\right|<2 \mathfrak{R}\left\{\frac{1+z}{1-z}\right\} \quad(z \in \mathbb{D}) .
$$

Then $f(z)$ is convex in one direction, and hence $f(z)$ is univalent in $\mathbb{D}$.

Proof Let $0 \leq r<1$. From hypothesis (1) we have

$$
\begin{aligned}
& \int_{0}^{2 \pi}\left|1+\Re\left\{\frac{z f^{\prime \prime}(z)}{f^{\prime}(z)}\right\}\right| \mathrm{d} \theta \\
& \quad<2 \int_{|z|=r}\left\{\mathfrak{R}\left\{\frac{1+z}{1-z}\right\}\right\} \mathrm{d} \theta \\
& \quad=2 \int_{0}^{2 \pi} \frac{1-r^{2}}{1-2 r \cos \theta+r^{2}} \mathrm{~d} \theta \\
& =4 \pi .
\end{aligned}
$$

Therefore, by Lemma $2, f(z)$ is convex in one direction in $\mathbb{D}$.

Example 1 Consider the function $f_{1}: \mathbb{D} \rightarrow \mathbb{C}$ defined by $f_{1}(z)=z /(1-z)$. Then we have

$$
1+\frac{z f_{1}^{\prime \prime}(z)}{f_{1}^{\prime}(z)}=\frac{1+z}{1-z} \quad(z \in \mathbb{D})
$$

Moreocer, we can easily check that condition (1) holds for the function $f_{1}$. Therefore, by Theorem 1 the function $f_{1}$ is convex in one direction and univalent in $\mathbb{D}$.

Theorem 2 Let $f(z) \in \mathcal{A}$ and suppose that

$$
\left|1+\frac{z f^{\prime \prime}(z)}{f^{\prime}(z)}\right| \leq\left|\frac{1+z}{1-z}\right| \quad(z \in \mathbb{D})
$$

Then $f(z)$ is convex in one direction in $|z|<r_{0}=0.251652 \cdots$, where $r_{0}$ is the root of the equation

$$
2 \pi\left(\frac{1+r}{1-r}\right)+4 \log \left(\frac{1+r}{1-r}\right)=4 \pi
$$


Proof Let $0 \leq r<1$. From inequality (2) we have

$$
\begin{aligned}
& \int_{0}^{2 \pi}\left|1+\Re\left\{\frac{z f^{\prime \prime}(z)}{f^{\prime}(z)}\right\}\right| \mathrm{d} \theta \\
& \quad \leq \int_{0}^{2 \pi}\left|1+\frac{z f^{\prime \prime}(z)}{f^{\prime}(z)}\right| \mathrm{d} \theta \\
& \quad \leq \int_{0}^{2 \pi}\left|\frac{1+z}{1-z}\right| \mathrm{d} \theta \\
& \quad \leq \int_{0}^{2 \pi}\left(\left|\frac{1-r^{2}}{1-2 r \cos \theta+r^{2}}\right|+\left|\frac{2 r \sin \theta}{1-2 r \cos \theta+r^{2}}\right|\right) \mathrm{d} \theta \\
& \quad \leq 2 \pi\left(\frac{1+r}{1-r}\right)+4 \log \left(\frac{1+r}{1-r}\right) .
\end{aligned}
$$

Define the function $g:[0,1) \rightarrow \mathbb{R}$ by

$$
g(r)=2 \pi\left(\frac{1+r}{1-r}\right)+4 \log \left(\frac{1+r}{1-r}\right) .
$$

Then $g(0)=2 \pi$ and $g(r) \rightarrow \infty$ as $r \rightarrow 1^{-}$. Also, we have that the function $g$ is increasing on $[0,1)$ since

$$
g^{\prime}(r)=\frac{4 \pi}{(1-r)^{2}}+\frac{8}{1-r^{2}}>0
$$

for all $r \in[0,1)$. Therefore, there exists a unique root $r_{0}$ in $[0,1)$ such that $g(r)=4 \pi$. Hence, we have

$$
\int_{0}^{2 \pi}\left|1+\mathfrak{R}\left\{\frac{z f^{\prime \prime}(z)}{f^{\prime}(z)}\right\}\right| \mathrm{d} \theta<4 \pi
$$

for $|z|<r_{0}$. It follows from Lemma 2 that $f(z)$ is convex in one direction in $|z|<r_{0}$.

Theorem 3 Let $f(z) \in \mathcal{A}$ and suppose that

$$
\left|\mathfrak{R}\left\{1+\frac{z f^{\prime \prime}(z)}{f^{\prime}(z)}\right\}-\frac{1}{2}\right|<\Re\left\{\frac{1+z}{1-z}\right\}+\frac{1}{2} \quad(z \in \mathbb{D}) .
$$

Then $f(z)$ is convex in one direction, and hence $f(z)$ is univalent in $\mathbb{D}$.

Proof Let $0 \leq r<1$. From hypothesis (4) we have

$$
\begin{aligned}
& \int_{|z|=r}\left\{\left|\mathfrak{R}\left\{1+\frac{z f^{\prime \prime}(z)}{f^{\prime}(z)}\right\}\right|-\frac{1}{2}\right\} \mathrm{d} \theta \\
& \leq \int_{|z|=r}\left|\mathfrak{R}\left\{1+\frac{z f^{\prime \prime}(z)}{f^{\prime}(z)}\right\}-\frac{1}{2}\right| \mathrm{d} \theta \\
& \quad<\int_{|z|=r}\left\{\mathfrak{R}\left\{\frac{1+z}{1-z}\right\}+\frac{1}{2}\right\} \mathrm{d} \theta \\
& =3 \pi .
\end{aligned}
$$


Therefore, we have

$$
\int_{|z|=r \mid}\left|\Re\left\{1+\frac{z f^{\prime \prime}(z)}{f^{\prime}(z)}\right\}\right| \mathrm{d} \theta<4 \pi
$$

for $|z|=r<1$. This shows that $f(z)$ is convex in one direction in $\mathbb{D}$.

Corollary 1 Let $f(z) \in \mathcal{A}$ and suppose that

$$
\left|\mathfrak{R}\left\{1+\frac{z f^{\prime \prime}(z)}{f^{\prime}(z)}\right\}\right|<\mathfrak{R}\left\{\frac{1+z}{1-z}\right\}+1 \quad(z \in \mathbb{D}) .
$$

Then $f(z)$ is convex in one direction, and hence $f(z)$ is univalent in $\mathbb{D}$.

Theorem 4 Let $f(z) \in \mathcal{A}$ and suppose that

$$
\left|1+\frac{z f^{\prime \prime}(z)}{f^{\prime}(z)}\right|<\sqrt{7} \quad(z \in \mathbb{D})
$$

Then $f(z)$ is convex in one direction, and hence $f(z)$ is univalent in $\mathbb{D}$.

Proof Let $0 \leq r<1$. From (5) we have

$$
\int_{|z|=r}\left|1+\frac{z f^{\prime \prime}(z)}{f^{\prime}(z)}\right|^{2} \mathrm{~d} \theta<14 \pi
$$

Note that

$$
\int_{|z|=r}\left(1+\frac{z f^{\prime \prime}(z)}{f^{\prime}(z)}\right)^{2} \mathrm{~d} \theta=\int_{|z|=r}\left\{1+2 \frac{z f^{\prime \prime}(z)}{f^{\prime}(z)}+\left(\frac{z f^{\prime \prime}(z)}{f^{\prime}(z)}\right)^{2}\right\} \mathrm{d} \theta=2 \pi
$$

and

$$
\int_{|z|=r} \overline{\left(1+\frac{z f^{\prime \prime}(z)}{f^{\prime}(z)}\right)^{2}} \mathrm{~d} \theta=2 \pi
$$

Therefore, from (6), (7), and (8) we have

$$
\begin{aligned}
& \int_{|z|=r}\left(1+\Re \frac{z f^{\prime \prime}(z)}{f^{\prime}(z)}\right)^{2} \mathrm{~d} \theta \\
& \quad=\frac{1}{4} \int_{|z|=r}\left[\left(1+\frac{z f^{\prime \prime}(z)}{f^{\prime}(z)}\right)^{2}+2\left|1+\frac{z f^{\prime \prime}(z)}{f^{\prime}(z)}\right|^{2}+\left(\overline{\left.\left.1+\frac{z f^{\prime \prime}(z)}{f^{\prime}(z)}\right)^{2}\right] \mathrm{d} \theta}\right.\right. \\
& \quad<8 \pi .
\end{aligned}
$$

Hence, applying the Cauchy-Schwarz inequality and (9), we get

$$
\int_{|z|=r}\left|1+\mathfrak{R} \frac{z f^{\prime \prime}(z)}{f^{\prime}(z)}\right| \mathrm{d} \theta \leq \sqrt{2 \pi \int_{|z|=r}\left|1+\mathfrak{R} \frac{z f^{\prime \prime}(z)}{f^{\prime}(z)}\right|^{2} \mathrm{~d} \theta}<4 \pi .
$$

This completes the proof of Theorem 4. 
Example 2 Consider the function $f_{2}: \mathbb{D} \rightarrow \mathbb{C}$ defined by

$$
f_{2}(z)=\frac{\sqrt{7}}{7}\left(\left(\frac{z+\sqrt{7}}{\sqrt{7}}\right)^{7}-1\right) \quad(z \in \mathbb{D})
$$

Then we have

$$
\left|1+\frac{z f_{2}^{\prime \prime}(z)}{f_{2}^{\prime}(z)}\right|=\left|\sqrt{7} \frac{\sqrt{7} z+1}{\sqrt{7}+z}\right|<\sqrt{7} \quad(z \in \mathbb{D}) .
$$

Hence, it follows from Theorem 4 that the function $f_{2}$ is convex in one direction. In fact, the function $f_{2}$ is convex in the direction of the positive real axis.

Applying the same method as that used in the proof of the aforementioned theorems and Lemma 1, we have the following sufficient conditions on analytic functions to be starlike in one direction.

Theorem $5 \operatorname{Let} f(z) \in \mathcal{A}$ and suppose that

$$
\left|\mathfrak{R}\left\{\frac{z f^{\prime}(z)}{f(z)}\right\}\right|<2 \mathfrak{R}\left\{\frac{1+z}{1-z}\right\} \quad(z \in \mathbb{D}) .
$$

Then $f(z)$ is starlike in one direction in $\mathbb{D}$.

Theorem 6 Let $f(z) \in \mathcal{A}$ and suppose that

$$
\left|\frac{z f^{\prime}(z)}{f(z)}\right| \leq\left|\frac{1+z}{1-z}\right| \quad(z \in \mathbb{D})
$$

Then $f(z)$ is starlike in one direction in $|z|<r_{0}=0.251652 \cdots$, where $r_{0}$ is the root of equation (3).

Theorem 7 Let $f(z) \in \mathcal{A}$ and suppose that

$$
\left|\mathfrak{R}\left\{\frac{z f^{\prime}(z)}{f(z)}\right\}-\frac{1}{2}\right|<\mathfrak{R}\left\{\frac{1+z}{1-z}\right\}+\frac{1}{2} \quad(z \in \mathbb{D}) .
$$

Then $f(z)$ is starlike in one direction in $\mathbb{D}$.

Theorem 8 Let $f(z) \in \mathcal{A}$ and suppose that

$$
\left|\frac{z f^{\prime}(z)}{f(z)}\right|<\sqrt{7} \quad(z \in \mathbb{D})
$$

Then $f(z)$ is starlike in one direction in $\mathbb{D}$. 


\section{Author details}

'University of Gunma, Hoshikuki-Cho 798-8, Chuou-Ward, Chiba, 260-0808, Japan. ${ }^{2}$ Department of Mathematics, Kyungsung University, Busan, 48434, Korea. ${ }^{3}$ Department of Applied Mathematics, Pukyong National University, Busan, 48513, Korea.

\section{Acknowledgements}

The authors would like to express their thanks to the editor Professor S Stevic and the referees for many valuable advices regarding a previous version of this paper. This research was supported by the Basic Science Research Program through the National Research Foundation of Korea (NRF) funded by the Ministry of Education, Science and Technology (No. 2011-0007037).

Received: 26 January 2016 Accepted: 2 March 2016 Published online: 05 March 2016

\section{References}

1. Robertson, MS: Analytic functions star-like in one direction. Am. J. Math. 58, 465-472 (1936)

2. Ozaki, S: On the theory of multivalent functions, II. Sci. Rep. Tokyo Kyoiku Daigaku, Sect. A 4, $45-86$ (1941)

3. Umezawa, T: On the theory of univalent functions. Tohoku Math. J. 7, 212-228 (1955)

4. Umezawa, T: Analytic functions convex in one direction. J. Math. Soc. Jpn. 4(2), 194-202 (1952)

5. Nunokawa, M, Sokół, J: Some simple conditions for univalence. C. R. Math. Acad. Sci. Soc. R. Can. 354, 7-11 (2015). doi:10.1016/j.crma.2015.10.001

6. Ogawa, S: Some criteria for univalence. J. Nara Gakugei Univ. 1(10), 7-12 (1961)

7. Shah, GM: On holomorphic functions convex in one direction. J. Indian Math. Soc. 37, 257-276 (1973)

\section{Submit your manuscript to a SpringerOpen ${ }^{\circ}$ journal and benefit from:}

- Convenient online submission

- Rigorous peer review

- Immediate publication on acceptance

- Open access: articles freely available online

- High visibility within the field

- Retaining the copyright to your article 